ent methods of determination were described. Of the invited papers, two, by members of the Bell Telephone Laboratories, dealt with the theory of secondary electrons; two, including a discussion by J. R. Zacharias of precision measurements, with molecular beams; two with the neutrino; three, "Microwave Resonance in Colour Centres", by E. E. Schneider, of the University of Durham, "Polarization of Nuclei in Metals by Magnetic Resonance", by A. W. Overhauser, and "The Solid-State Cyclotron", by C. Kittel, with magnetic resonance; and two with cryogenics. In addition, P. W. Bridgman spoke of the effects of pressure on twelve rare-earth metals, W. A. Pomerantz on cosmic radiation at very high altitudes near the geomagnetic equator, and E. W. Corson on the properties of new $V$-particles.

The programme of the meeting of the American Association of Physics Teachers (Amer. J. Phys., 22, 426 ; 1954) consisted of two panel and one roundtable discussions, three invited papers, twenty-seven contributed papers, a film session and a business moeting in addition to the joint sessions with the Physical Society. C. N. Hoyler, of the Radio Corporation of America, gave a demonstration of colour television in which recent developments of the R.C.A. were described and illustrated. In the panel discussion on "Research Subsidies and College Teaching", various problems involved in combining teaching and research were considered; and in the session devoted to a discussion of the functions and mission of the Association, H. K. Schilling reviewed the history of the Association and T. H. Osgood, editor of the American Journal of Physics, spoke on "What goes into the Journol". At the business meeting of the Association on January 30, it was agreed to confer honorary membership on D. Bronk, former president of Johns Hopkins University, president of the National Research Council and head of the Rockefeller Institute for Medical Research; and for noteworthy service to the Association T. D. Cope, P. Kirkpatrick, C. J. Overbeck and M. H. Trytten were voted special citations. The need for increased income to cover current expenses was emphasized and a change in the by-laws was approved to permit the increase of subscriptions to a maximum of eight dollars per annum. The following were elected to hold office for 1954: President, P. M. Marsh; President-elect, R. R. Palmer ; Treasurer, F. W. Sears ; and Secretary, R. F. Paton.

\section{BREEDING FOR BEEF IN TROPICAL AND SUB-TROPICAL CLIMATES}

CLIMATE, and temperature in particular, is 1 directly concerned with the success or failure of animal production in tropical and sub-tropical territories. It has boen established in various parts of the world that wide variations exist between different breeds and types of farm animals in their ability to adapt themselves to the climatic conditions peculiar to a particular environment. Because of their low powers of adaptability, the introduction of European breeds has failed in most tropical territories, and this has focused the attention of research workers on the wide range of ecological problems confronting the livestock industry in those parts of the world (D. M. Joubert, Colonial Plant and Animal Products, 4, No. 1 ; 1954).
In the breeding of livestock for tropical and subtropical environments, it is important to pay attention to the conformational features and breed characteristics which promote adaptability. First, for maximum radiation to be possible, the animal must possess a large skin area. It is a noticeable feature of cattle native to tropical regions that they have a well-developed dewlap which extends down to the navel, together with easily extensible skin folds which are especially numerous in the neck and thoracic regions. These characters are illustrated in the Afrikaner bull and cow, a tropical breed indigenous to South Africa and belonging to the lateral-horned zebu group. In the zebu cattle of India the ears, too, are considerably larger than those of Bos taurus (European) cattle.

Hair covering, which includes the thickness of the coat and structure of the hair fibre, is of equal importance in heat regulation. The critical temperature of smooth-coated cattle lies several degrees below that of woolly-coated individuals. In recent investigations, Bonsma and his associates have showed that, with the progeny of a mutant woollycoated Afrikaner bull, tropical degeneration is possible also in the native stock should they lack any of the essential attributes which promote adaptability.

Earlier studies showed that a light-coloured coat is superior to black in the dry tropies. White or cream-coloured individuals do even better than reds provided that the hide is protected by pigmentation. Colour is regarded as playing a part in heat regulation by influencing the amount of sunlight that is reflected from the skin. Dark colours presumably tend to increase the heat load of the animal. Measurements of the reflexion of light from various coat colours indicate that the coat of white Afrikaners absorbs about 45 per cent of the solar radiation impinging upon it, as against 89 per cent in the case of the black hairy coat of Aberdeen-Angus cattle, 78 per cent of red Afrikaners, 93 per cent of red Sussex cattle and 50 per cent of cream-coloured Simmenthalers.

The effect of a tropical environment on the conformation of an unadapted beast is shown by comparing an unadapted woolly-coated Shorthorn cow with $\&$ normal individual of similar breeding and age. Whereas the beef Shorthorn is normally a digestive type - that is, relatively round in cross-section and equally deep through both chest and belly-the exotic animal in tropical environments tends to develop into a respiratory type. This may be explained by the fact that the Shorthorn has a limited skin area and also a woolly coat, both lowering its capacity of heat loss. The burden of thermolysis thus falls almost entirely on the water-evaporating capacity of the lungs, and tho obvious conformational change to take place is an increased lateral depth of chest, flattening of ribs and a contracted belly.

Joubert has also considered the effects of the nutritional environment on cattle in tropical countries. In regions with fluctuations in the nutritive value of the natural pastures, as well as with high summer temperatures, the problem of adapting the exotic beast is complicated. As the body tem. perature increases during the hot months, meta. bolism is stepped up, the time spent in grazing is reduced and that of lying in the shade increased. In short, the animal suffers from a constant fever or hyperthermia. If the grazing is exceptionally 
poor, it is quite impossible for the leeway to be made up during the period of the year when temperate cattle are not affected by the climatic conditions. In the case of the animal surviving, it virtually exists in a state of chronic undernourishment.

Although animal breeding still presents many problems, both genetical and physiological, the knowledge gained from scientific approaches to the subject during the past three decades has made it considerably more exact and practicable. Scientific investigations provide the evidence to prove that the high-grade European breeds of cattle, which are the result of selection for maximum performance under temperate climatic conditions, do not maintain the same qualities when transferred beyond the borders of their natural habitat or of regions with approximately similar conditions. Hence, improvement of animal production by merely replacing the cattle native to tropical and sub-tropical regions with highly improved breeds of temperate origin is out of the question.

'The genetical variation occurring within the exotic breeds makes possible the selection of individuals possessing those attributes required for increased adaptability to tropical conditions. By basing their selection on such characters as coat covering and colour, Bonsma and his associates have achieved considerable success in increasing the heat tolerance of British beef breeds, especially Herefords, at the Mara Research Station, which is situated in the dry-tropical zone of South Africa. The limit of such a policy is indicated, however, by the fact that when these investigations were repeated at the Messina Experimental Farm, situated in a lowerlying tropical belt, they met with complete failure. The high mortality-rate of the British beef breeds in the tropics, compared with the indigenous stock, also seriously limits the value of breeding adapted strains of European cattle.

Cross-breeding between the indigenous stock and exotic types presents a second possibility. During the early stages of livestock improvement in tropical regions, a policy of grading up with European breed bulls was advocated. The first generation cross-breds excelled because of hybrid vigour and the genetical dominance of heat-tolerant characters; as the percentage of indigenous blood diminished in subsequent generations, the cross-breds also deteriorated.

The most constructive and successful of all long. term policies for livestock breeding in tropical and sub-tropical regions seems to lie in improvement of the indigenous stock by means of judicious selection. The high standard of animal production of temperate countries can never be attained in tropical regions, while the indigenous stock of the tropics are inherently of lower productivity than their cousins of the temperate zone. Nevertheless, in the Afrikaner, it has been demonstrated that improvement of beef qualities is possible without any loss of those characters which give the breed superiority over exotic types in the tropies and sub-tropics. As for its slower growth and maturing characters, these actually are inherent qualities of practical significance and value in the production of beef under varying conditions of climate, and especially nutrition. As a result of a slower growth-rate, the influence of periodic nutritional depressions is not so acute as is the case with the rapidly growing, early-maturing breeds of beef cattle.

\section{LIBRARY CO-OPERATION IN BRITAIN}

$\mathrm{T}$

HE final recommendations on Library Cooperation of the Joint Working Party set up by the National Central Library and the National Committee on Regional Library Co-operation have now been issued in the name of the Library and the National Committee*. The working party was satisfied that the general structure of library cooperation and inter-lending is sound, and recommended that university and special libraries outside the area covered by the London Union Catalogue and the South Eastern Region should become participant members of their appropriate regional system on the basis on which many of them at present co-operate, and that they should also retain the existing right to send applications direct to the National Central Library. Within this area, however, it recommends that, as at present, university libraries should apply direct to the National Central Library for inter-library loans, but special libraries should have direct relations with the Central Library; and that membership of the London and South Eastern Regional Library systems should remain restricted to the public library authorities within the area.

The working party is also satisfied that the Union Catalogue is necessary for effective inter-lending, and recommends that the existing Union Catalogue should be brought up to date. The Yorkshire, North Western and West Midland Regions should consider how best they may provide Union Catalogues of stock prior to a specified date, which would be adequate for regional and national purposes, and from that date all regional union catalogues should contain entries for British books, and for all other books published outside Great Britain, and those published in Great Britain prior to the specified date. The working party also recommends that each region should consider what co-operative arrangements could be made to ensure that all applications to the bureaux for current British material are supplied from resources within the region, and to ensure that at least one copy of every non-fiction book in the region is retained permanently in that region. Each region should also investigate the methods by which the range of periodicals can be improved and their permanent preservation ensured.

The working party recommends the exclusion from the scope of all inter-lending agencies of: $(a)$ those works of English and American fiction outside the scope of the joint fiction reserves to be set up in the various regions; $(b)$ sets of copies of plays for acting and reading outside the scope of any joint play collections to be set up in the regions; (c) children's books ; $(d)$ 'quick reference' books (that is, dictionaries, atlases, encyclopædias, etc., likely to be regularly consulted in a library); (e) current yearbooks, annuals and directories; $(f)$ current numbers of periodicals.

It also suggests that all books in print costing 258 . or less should be outside the scope of the National Central Library.

The working party considers that any long-term plans for bringing these regional bureaux to a state of greater efficiency and maintaining them adequately

- Recommendations on Library Co-operation. Pp. 8. (London: National Central Library and National Committee on Regional Library Co-operation, 1954.) 